\title{
Disability in people with chronic low back pain treated in primary care
}

\author{
Incapacidade em pessoas com \\ dor lombar crônica atendidas \\ na atenção primária
}

Micheline Henrique Araújo da Luz Koerich $\mathbb{D}^{1 *}$

Betina Hörner Schlindwein Meirelles (D) ${ }^{2}$

Maria Elena Echevaría-Guanilo (1) ${ }^{2}$

Ana Lúcia Danielewicz (D) ${ }^{2}$

Debora Soccal Schwertner (iD ${ }^{1}$

Rodrigo José Knabben (10 ${ }^{3}$

${ }^{1}$ Universidade do Estado de Santa Catarina (UDESC), Florianópolis, SC, Brazil

2 Universidade Federal de Santa Catarina (UFSC), Florianópolis, SC, Brazil

${ }^{3}$ Secretaria Municipal de Saúde (SMS), Florianópolis, SC, Brazil
Date of first submission: November 29, 2020

Last received: August 16, 2021

Accepted: August 18, 2021

Associate editor: Angélica Cavalcanti de Sousa

*Correspondence: michelinekoerich@gmail.com

\begin{abstract}
Introduction: Low back pain is a common musculoskeletal problem and can become chronic, with varying degrees of disability. Objective: Analyze the factors associated with disability in individuals with chronic low back pain (CLBP), treated in primary care. Methods: Cross-sectional study with 82 basic health unit ( $\mathrm{BHU}$ ) users in the municipality of Florianópolis (Brazil) with CLBP. Sociodemographic and clinical variables, health status, lifestyle and treatment were investigated. Self-rated disability was investigated using the Roland Morris questionnaire ( $\geq 14$ points). The $\chi^{2}$ or Fisher's exact tests were used in inferential analysis for univariate association and the presence of disability. Multivariate association was analyzed by logistical regression, estimating the crude and adjusted odds ratios (OR) and their respective confidence intervals (95\% Cl). Results: Adults aged 40-59 years had a greater chance of developing disability (OR: 8.17; 95\%: 1.21 55.0), while professionally active individuals (OR: 0.08; $95 \% \mathrm{Cl}: 0.02-0.33)$ who reported engaging in physical activity $\geq 3$ times a week (OR: 0.19; IC95\%: $0.04-0.83$ ) had less chance of the same outcome when compared to the other participants. Conclusion: Factors related to disability were age, employment status and frequency of physical activity. Incentive strategies to return to work and engage in regular physical activity and exercise should be encouraged.
\end{abstract}

Keywords: Low back pain. Physical and functional performance. Primary care. 


\section{Resumo}

Introdução: A dor lombar é um problema musculoesquelético comum e pode tornar-se uma condição crônica, com níveis variados de incapacidade. Objetivo: Analisar os fatores associados à incapacidade em indivíduos com dor lombar crônica, acompanhados na Atenção Primária à Saúde. Métodos: Estudo transversal realizado com 82 usuários das unidades básicas de saúde do município de Florianópolis (Brasil), com queixa de dor lombar crônica. Foram investigadas variáveis sociodemográficas e clínicas, condições de saúde, estilo de vida e tratamento. A incapacidade percebida foi mensurada pelo questionário Roland Morris ( $\geq 14$ pontos). Na análise inferencial foram utilizados os testes $\chi^{2}$ ou exato de Fisher para associação univariada e presença de incapacidade. A associação multivariável foi analisada por meio do modelo de regressão logística, estimando-se os valores das odds ratio (OR) brutas e ajustadas e seus respectivos IC $95 \%$.

Resultados: Indivíduos adultos com 40-59 anos tiveram maiores chances de ter incapacidade (OR: 8,17; IC95\%: 1,21 - 55,0), enquanto aqueles que eram profissionalmente ativos (OR: 0,08; IC95\%: 0,02 - 0,33) e que relataram praticar atividade física com frequência $\geq 3$ vezes na semana (OR: 0,19; IC95\%: 0,04 $0,83)$ tiveram menores chances do mesmo desfecho quando comparados aos demais. Conclusão: Os fatores relacionados à incapacidade foram idade, situação profissional e frequência de atividade física. Estratégias de incentivo de retorno ao trabalho e prática de atividade física e de exercícios devem ser incentivadas.

Palavras-chave: Dor lombar. Desempenho físico funcional. Atenção Primária à Saúde.

\section{Introduction}

Low back pain, a common musculoskeletal problem, can have a considerable social and economic impact and it is the main cause of activity limitations and workplace absenteeism. ${ }^{1}$ Although low back pain typically resolves in a few weeks, it persists in approximately $15 \%$ of people ${ }^{2}$ and becomes chronic, with varying degrees of disability.

Disability related to chronic low back pain (CLBP), characterized by difficulty performing activities of daily living at home and/or work, ${ }^{3}$ is a public health problem because it directly affects the social lives, careers and families of individuals. ${ }^{3-6}$ As a result, CLBP is one of the most common complaints treated in primary care ${ }^{7,8}$ and requires multidisciplinary strategies aimed at caring for this population.

Several studies have demonstrated that greater degrees of disability are directly linked to poor recovery..$^{9,10}$ The most prominent CLBP-related disability factors established in the literature are pain intensity, certain sociodemographic (sex and unemployment) and psychosocial factors. 3,11,12 However, given the multiple factors that contribute to CLBP, other health-related aspects and behaviors should also be investigated.

In order to broaden knowledge on aspects related to disability in CLBP, and given the potential usefulness of this information in guiding health promotion, prevention and rehabilitation initiatives, this study aimed to analyze factors associated with disability in people with CLBP treated in primary care services.

\section{Methods}

\section{Study design}

This was a descriptive cross-sectional study with users of primary care services, conducted between May 2014 and July 2015.

\section{Selection criteria}

Participants were aged 18 years and over, who had complained of low back pain for more than six months and had been treated at Basic Health Units (BHUs) for more than 12 months. Excluded were people with health problems that might compromise their responses during the interview (cognitive impairment, such as in cases of severe neurological sequelae) and/or make it impossible to understand the questions, and those who withdrew from the study after completing only part of the interview.

\section{Data collection}

The participants were approached while attending self-care and physical activity (PA) groups in a health district of Florianópolis, Santa Catarina state, which consists of $12 \mathrm{BHUs}$ and 27 family healthcare (FHC) teams and has an estimated population of 98,486 inhabitants. The researchers visited 34 self-care (for chronic pain) and PA groups to publicize the study and identify individuals with CLBP who might be interested in taking part in the 
study. Those who met the selection criteria were asked to fill out and sign a form providing contact details to arrange an interview for data collection.

The interviews were scheduled by telephone and conducted at the relevant BHU $(n=69)$ or the participants' homes $(n=12)$. Data were collected at inperson interviews carried out by two physiotherapists and a nursing student.

\section{Data collection instruments}

Two data collection instruments were applied: a structured survey compiled for the study and the Roland Morris Questionnaire (RMQ) to assess the degree of disability.

The structured questionnaire aimed to obtain information on sociodemographic (sex, age, schooling level, employment status and household income) and behavioral characteristics (frequency of PA, smoking history and body mass index), clinical characteristics and health status (self-perceived health, presence of herniated disk, other chronic diseases and sleep quality), and treatmentrelated aspects (medication and self-care advice).

The RMQ, validated and adapted to the Brazilian population, ${ }^{13}$ was applied to measure self-rated disability in people with low back pain. It contains 24 sentences related to activities on daily living, with the final score varying from 0 (no disability) to 24 points (severe disability) based on the number of affirmative responses. In the present study, 14 points was used as a cutoff to establish the presence of disability. ${ }^{14}$

\section{Analysis of the variables}

Data collection was organized according to age (up to 39 years old; 40 to 59 years old; 60 years or older) and schooling level ( 0 - 4 years; 5 - 8 years; 9 11 years; 12 years or more). In regard to employment status, participants on sick leave, unemployed or retired at the time of the study were considered "inactive" and those who were working as "active". Household income was established based on minimum wage (MW) and classified as low $\leq 3 \mathrm{MWs}$ and medium/high $>3$. Physical activity was categorized according to weekly frequency (never; $\leq 2$ times a week; $\geq 3$ times a week). Three categories were considered for smoking history: nonsmoker, ex-smoker and smoker. Body mass index (BMI) was calculated and classified as normal weight (18.5 to
24.9), overweight (25 to 29.9) and obese ( $\geq 30) .{ }^{15}$ Selfperceived health and sleep quality were assessed by the questions: How do you view your health? and How do you view your sleep quality? The answers to both were dichotomized into good (excellent/good/fair) and poor (bad/very bad).

The presence of herniated disks was confirmed by diagnostic imaging reports. Participants were deemed to have other chronic diseases when they reported being treated for at least one of the following conditions: high blood pressure, diabetes mellitus, chronic obstructive pulmonary disease, fibromyalgia, depression/anxiety. The use of medication was assessed by the question: Are you currently using medication to control or relieve pain? The variable "self-care advice" was evaluated based on the question: When being treated by healthcare professionals, are you given advice on how to care for your low back pain?

\section{Data analysis}

The data were transferred to tables in Microsoft Excel 2010 (two researchers typed in the data and the tables were then compared), validated and then analyzed using Stata software version 13.0 (Stata Corp, College Station, Texas, USA). Absolute and relative frequencies were calculated for all the variables assessed. The $\chi^{2}$ or Fisher's exact tests were used in inferential analysis for univariate association and the presence of disability. Multivariate association was analyzed by logistical regression, estimating the crude and adjusted odds ratios (OR) and their respective confidence intervals $(95 \% \mathrm{Cl})$. The hierarchical model was applied in multivariate analysis to adjust the dependent to the explanatory variables. The variables were input into the model according to four adjustment levels: 1) sociodemographic; 2) behavioral; 3) health status; 4) treatment. The criterion adopted for variable input in univariate analysis was $p \leq 0.20$. In multivariate analysis, adjusted variables were those at the same or a superior level, with $p<0.05$.

\section{Ethical aspects}

All the participants provided written informed consent. The study was approved by the Research Ethics Committee of Santa Catarina State, Brazil (protocol no. 252540 of $04 / 23 / 2013$ ) and is in line with Resolution $466 / 12$, which governs research involving humans. 


\section{Results}

At the end of the recruitment process, $82 \mathrm{BHU}$ users participated in the interviews and were included in the study (Figure 1).

Most of the participants were women (80.5\%), with an average age of 55.5 years (standard deviation - SD $=12.6$ years), 12 or more years of schooling and a low household income. In terms of employment status, $51.2 \%$ were not employed at the time of the interview.

With respect to low back pain, the average duration of symptoms was 10 years ( $S D=9.67$ years). The average score on the RMQ was 12.3 points (SD $=6.8$ ) and the prevalence of disability $45.1 \%(95 \% \mathrm{Cl}: 34.5$ - 56.1).Univariate analysis demonstrated statistically significant associations for the following variables: age, employment status, frequency of PA, self-perceived health, presence of chronic diseases, sleep quality, use of medication and receiving self-care advice, as shown in Table 1.

The variables still significantly associated with the presence of disability after adjustment were age, employment status and frequency of PA. The results indicated that adults between 40 and 59 years old were 8.17 times more likely to exhibit disability when compared with 39-year-olds. Individuals who were employed and engaged in physical activity three or more times a week had a 92 and $81 \%$ lower chance of developing disability than those deemed inactive or who never took part in PA, respectively (Table 2).

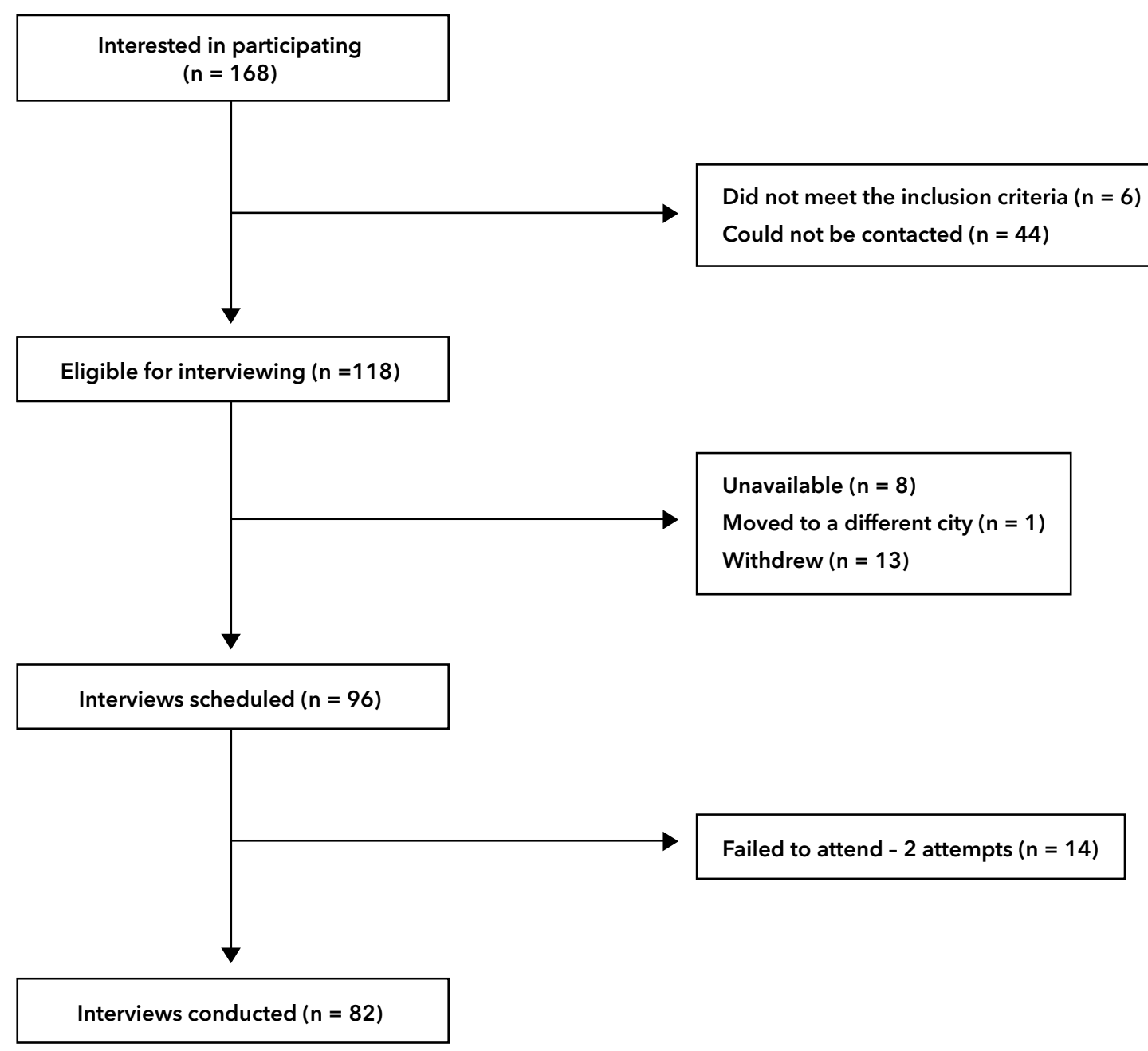

Figure 1 - Flowchart of the recruitment process and sample composition. 
Table 1 - Characterization of participants and prevalence of disability (univariate analysis)

\begin{tabular}{|c|c|c|c|}
\hline Variables & Total n (\%) & Disability (\%) & p-value \\
\hline \multicolumn{4}{|l|}{ Sociodemográficas } \\
\hline $\operatorname{Sex}(n=82)$ & & & $0.20 \dagger$ \\
\hline Men & $16(19.5)$ & $5(13.5)$ & \\
\hline Women & $66(80.5)$ & $32(86.5)$ & \\
\hline Age $(n=82)$ & & & $0.01 * \star$ \\
\hline$\leq 39$ years & $10(12.2)$ & $3(8.1)$ & \\
\hline 40-59 years & $40(48.8)$ & $25(67.6)$ & \\
\hline$\geq 60$ years & $32(39.0)$ & $0(24.3)$ & \\
\hline Schooling level $(n=80)$ & & & 0.34 \\
\hline $0-4$ years & $16(20.0)$ & $6(16.2)$ & \\
\hline $5-8$ years & $23(28.7)$ & $14(37.9)$ & \\
\hline 9-11 years & $12(15.0)$ & $6(16.2)$ & \\
\hline$\geq 12$ years & $29(36.3)$ & $11(29.7)$ & \\
\hline Employment status ( $n=82$ ) & & & $<0.01 \dagger^{\star \star}$ \\
\hline Inactive & $42(51.2)$ & $26(70.3)$ & \\
\hline Active & $40(48.8)$ & $11(29.7)$ & \\
\hline Household income $(n=81)^{\star}$ & & & $0.37 \dagger$ \\
\hline Low & $46(56.1)$ & $23(62.2)$ & \\
\hline Medium/High & $35(42.7)$ & $14(37.8)$ & \\
\hline \multicolumn{4}{|l|}{ Behavioral } \\
\hline Frequence of physical activity $(n=82)$ & & & $<0,01^{\star \star}$ \\
\hline Never & $45(54.9)$ & $27(73.0)$ & \\
\hline$\leq 2 \times$ week & $15(18.3)$ & $5(13.5)$ & \\
\hline$\geq 3 \times$ week & $22(26.8)$ & $5(13.5)$ & \\
\hline Smoking history $(n=82)$ & & & 0.14 \\
\hline Never & $37(45.1)$ & $13(35.1)$ & \\
\hline Ex-smoker & $33(40.2)$ & $16(43.2)$ & \\
\hline Smoker & $12(14.6)$ & $8(21.6)$ & \\
\hline BMI $(n=81)$ & & & $0.04^{\star \star}$ \\
\hline Normal weight $\left(\leq 24 \mathrm{~kg} / \mathrm{m}^{2}\right)$ & $22(27.1)$ & $6(16.2)$ & \\
\hline Overweight (25 - 29 kg/m²) & $36(44.4)$ & $16(43.2)$ & \\
\hline Obese $\left(\geq 30 \mathrm{~kg} / \mathrm{m}^{2}\right)$ & $23(28.4)$ & $15(40.5)$ & \\
\hline \multicolumn{4}{|l|}{ Health status } \\
\hline Self-perceived health $(n=81)$ & & & $<0.01 \dagger^{\star \star *}$ \\
\hline Good & $56(69.1)$ & $19(51.4)$ & \\
\hline Poor & $25(30.9)$ & $18(48.6)$ & \\
\hline Presence of herniated disk $(n=82)$ & & & $0.25 \dagger$ \\
\hline No & $52(63.4)$ & $21(56.8)$ & \\
\hline Yes & $30(36.6)$ & $16(43.2)$ & \\
\hline Other chronic diseases $(n=82)$ & & & $<0.01 \dagger^{\star \star}$ \\
\hline No & $13(15.9)$ & $6(16.2)$ & \\
\hline Yes & $69(84.1)$ & $31(83.8)$ & \\
\hline Sleep quality $(n=82)$ & & & $0.05 十^{\star \star \star}$ \\
\hline Good & $27(32.9)$ & $8(21.6)$ & \\
\hline Poor & $55(67.1)$ & $29(78.4)$ & \\
\hline \multicolumn{4}{|l|}{ Treatment } \\
\hline Use of medication $(n=82)$ & & & $0.06 十^{\star \star}$ \\
\hline No & $24(29.3)$ & $7(18.9)$ & \\
\hline Yes & $58(70.7)$ & $30(81.1)$ & \\
\hline Self-care advice $(n=82)$ & & & $0.03 \dagger^{\star \star}$ \\
\hline No & $23(28.0)$ & $6(16.2)$ & \\
\hline Yes & $59(72.0)$ & $31(83.8)$ & \\
\hline
\end{tabular}

Note: *Household income was established based on minimum wage (MW) and classified as low $\leq 3 \mathrm{MWs}$ and medium/high $>3$. BMI $=\mathrm{Body}$ mass index. $\dagger x^{2}$ test Fisher's exact test. ${ }^{\star *}$ Significant $p$-value $(\leq 0.05)$. 
Table 2 - Association between self-rated disability, sociodemographic variables and health status (multivariate analysis)

\begin{tabular}{|c|c|c|c|c|}
\hline Variables & $\begin{array}{c}\text { Crude } \\
\text { OR (IC 95\%) }\end{array}$ & $\mathbf{p}$ & $\begin{array}{c}\text { Adjusted } \\
\text { OR (IC 95\%) }\end{array}$ & $\mathbf{p}$ \\
\hline Sex & & 0.20 & & 0.28 \\
\hline Men & 1.00 & & 1.00 & \\
\hline Women & $2.07(0.64-6.61)$ & & $2.06(0.57-7.96)$ & \\
\hline Age (years) & & $0.01^{*}$ & & $0.01^{*}$ \\
\hline$\leq 39$ & 1.00 & & 1.00 & \\
\hline $40-59$ & $3.88(0.87-17.40)$ & & $8.17(1.21-55.00)$ & \\
\hline$\geq 60$ & $0.91(0.19-4.33)$ & & $0.76(0.12-4.60)$ & \\
\hline Employment status & & $0.02^{*}$ & & $0.01^{*}$ \\
\hline Inactive & 1.00 & & 1.00 & \\
\hline Active & $0.23(0.91-0.59)$ & & $0.08(0.02-0.33)$ & \\
\hline Frequency of physical activity & & $0.01^{\star}$ & & $0.01^{*}$ \\
\hline Never & 1.00 & & 1.00 & \\
\hline$\leq 2 \times$ week & $0.33(0.09-1.13)$ & & $0.08(0.01-0.65)$ & \\
\hline$\geq 3 \times$ week & $0.19(0.06-0.62)$ & & $0.19(0.04-0.83)$ & \\
\hline Smoking history & & 0.15 & & 0.29 \\
\hline Never & 1.00 & & 1.00 & \\
\hline Ex-smoker & $1.73(0.66-4.53)$ & & $2.84(0.68-11.80)$ & \\
\hline Smoker & $3.69(0.93-14.60)$ & & $2.94(0.39-21.90)$ & \\
\hline BMI & & $0.04^{\star}$ & & 0.11 \\
\hline Normal weight ( $\leq 24 \mathrm{~kg} / \mathrm{m}^{2}$ ) & 1.00 & & 1.00 & \\
\hline Overweight (25 - $\left.29 \mathrm{~kg} / \mathrm{m}^{2}\right)$ & $2.13(0.67-6.70)$ & & $2.76(0.55-13.70)$ & \\
\hline Obese $\left(\geq 30 \mathrm{~kg} / \mathrm{m}^{2}\right)$ & $4.99(1.40-17.80)$ & & $5.92(1.12-31.20)$ & \\
\hline Self-perceived health & & $<0.01^{*}$ & & 0.11 \\
\hline Good & 1,00 & & 1,00 & \\
\hline Poor & $5.00(1.78-14.00)$ & & $3.06(0.75-12.46)$ & \\
\hline Other chronic diseases & & $<0.01^{*}$ & & 0.23 \\
\hline No & 1.00 & & 1.00 & \\
\hline Yes & $13.1(1.61-106.20)$ & & $2.43(0.56-10.49)$ & \\
\hline \multicolumn{5}{|l|}{ Sleep quality } \\
\hline Good & 1.00 & $0.05^{\star}$ & 1.00 & 0.59 \\
\hline Poor & $2.64(0.99-7.06)$ & & $1.46(0.36-5.93)$ & \\
\hline Use of medication & & $0.06^{*}$ & & 0.40 \\
\hline No & 1.00 & & 1.00 & \\
\hline Yes & $2.60(0.94-7.21)$ & & $1.72(0.47-6.36)$ & \\
\hline Advice ${ }^{\star \star}$ & & $0.03^{*}$ & & 0.11 \\
\hline No & 1.00 & & 1.00 & \\
\hline Yes & $3.13(1.08-9.07)$ & & $3.08(0.76-12.54)$ & \\
\hline
\end{tabular}

Note: $\mathrm{OR}=$ odds ratios; $\mathrm{BMI}=$ Body mass index; ${ }^{\star S}$ Significant $\mathrm{p}$ value $(\leq 0.05)$. ** Guidelines on self-care for pain. 


\section{Discussion}

The results demonstrated that the variables associated with disability among participants in the present study were age and employment status (sociodemographic), as well as more frequent PA (behavioral).

With respect to age, 40 to 59-year-olds had a greater chance of developing disability than younger (up to 39 years) and older adults. Studies that investigate chronic low back pain have produced controversial results on the relationship between age and disability. Although previous research ${ }^{3,15}$ found that age was not related to disability, only adults were investigated. On this same topic, other authors ${ }^{16}$ observed no association between advanced age and disability at baseline; however, the former was a predictor of disability at a one-year followup assessment. Pain intensity seems to be related to disability and is greater in younger than older adults. ${ }^{17}$ It has been suggested that pain explains most of the variance in young individuals, but factors such as selfefficacy, mood, muscle strength and physical fitness may contribute to self-rated disability, producing different results in adults and the elderly. It can be difficult to identify disability caused specifically by pain, suggesting that the presence of other types of pain and morbidities may affect perceived functional disability caused by CLBP. ${ }^{16}$

Another factor correlated with disability was employment status, whereby people who were employed at the time of the study had less chance of exhibiting disability. Other studies that analyzed patients with CLBP found a greater risk of disability in unemployed individuals, ${ }^{10,18,19}$ and that being employed seems to be related to better recovery from symptoms caused by CLBP. ${ }^{10}$

It is important to note that, in the present study, individuals deemed inactive were not only those without paid work, but also those who had retired or were on sick leave, suggesting that all these participants have a greater probability of developing disability. Being unemployed may be related to disability because individuals in this situation tend to focus more on pain and often feel socially ostracized. ${ }^{3}$ Those who are still working, even if only part-time, are generally more physically and socially active, factors related to better functional recovery. ${ }^{10}$

Among the behavioral factors assessed, PA was linked to disability, indicating that people with CLBP who did not engage in PA were at greater risk of functional disability. These results corroborate those obtained in a systematic review ${ }^{20}$ which also demonstrated an association between PA and disability. It is important to underscore that although the World Health Organization ${ }^{21}$ recommends 150 minutes of moderate PA a week to maintain cardiorespiratory and muscle function, the results obtained here suggest that less exercise time may still be beneficial to this population.

The correlation between physical inactivity and disability can be interpreted based on the fearavoidance model, which deals with how people interpret their pain. ${ }^{22}$ Pain catastrophizing can result in a fear of pain and/or a new injury, leading to hypervigilance and avoidance in situations that might involve a greater probability of pain or injury, such as PA and/or other leisure activities that require movement and exercise. ${ }^{23}$

Approximately half of the sample in the present study did not engage in any form of exercise. Lifestyles devoid of PA (leisure, work, household chores) and/ or exercise are typically linked to sedentary behavior, which has been identified as one of the factors related to other chronic conditions (diabetes, hypertension, cardiovascular disease, depression). ${ }^{24}$ However, sedentary behavior can be modified by health promotion practices and strategies, such as those provided under primary care, which encourage leisure-time PA and exercise. In this respect, the National Health Promotion Policy in Brazil promotes the expansion of initiatives that encourage physical activity in communities, ${ }^{25}$ and although these programs target specific populations, it is suggested that they should also be offered to individuals with chronic pain.

In the case of people with CLBP, PA and exercise are recommended as part of the treatment plan due to their beneficial effects in alleviating pain and reducing disability. ${ }^{8}$ Moderate to vigorous leisure-time PA and/or exercise can reduce pain and disability. ${ }^{26}$ Additionally, PA is associated with physical and mental well-being and social inclusion, ${ }^{27}$ making it a potentially useful health promotion tool for populations with chronic pain.

Despite its limitations (cross-sectional design, convenience sampling and self-reported measurements), which make it difficult to generalize the results, the present study is relevant in that it broadens research on factors associated with functional disability in a group of people with CLBP treated in primary care, a scenario still little investigated in some countries, such as Brazil. Thus, in-depth studies on disability in primary care 
users are needed, particularly in relation to predictors of disability and modifiable risk factors, which can be prevented and targeted by healthcare professionals. We further suggest the use of instruments to conduct more detailed investigations on other exercise-related parameters (frequency, duration, intensity, modality).

\section{Conclusion}

The results obtained here suggest that age, employment status and frequency of physical activity are factors associated with disability in people with CLBP. Healthcare strategies for this population should focus on encouraging physical activity and/or exercise and returning to work.

\section{Acknowledgments}

The authors are grateful to the Research Support Foundation of Santa Catarina State - FAPESC (Santa Catarina, Brazil) for the funding received.

\section{Authors' contributions}

Conceptualization: MHALK e BHSM. Research design: MHALK, BHSM, DSS e RJK. Data analysis and interpretation: MHALK, MEEG, ALD, DSS. Writing: MHALK, BHSM, MEEG, ALD, RJK. Review: MHALK e BHSM. All authors approved the final version.

\section{References}

1. Hoy D, March L, Brooks P, Blyth F, Woolf A, Bain C, et al. The global burden of low back pain: Estimates from the Global Burden of Disease 2010 study. Ann Rheum Dis. 2014;73(6):968-74. DOI

2. Gore M, Sadosky A, Stacey BR, Tai KS, Leslie D. The burden of chronic low back pain: Clinical comorbidities, treatment patterns, and health care costs in usual care settings. Spine (Phila Pa 1976). 2012;37(11):E668-77. DOI

3. Salvetti MG, Pimenta CAM, Braga PE, Corrêa CF. Disability related to chronic low back pain: Prevalence abd associated factors. Rev Esc Enferm USP. 2012;46(Esp):16-23. DOI
4. Souza L, Oliver Frank A. Patients' experiences of the impact of chronic back pain on family life and work. Disabil Rehabil. 2011;33(4):310-8. DOI

5. Bailly F, Foltz V, Rozenberg S, Fautrel B, Gossec L. The impact of chronic low back pain is partly related to loss of social role: a qualitative study of 25 patients. Osteoarthr Cartil. 2014;22:S438. DOI

6. Hartvigsen J, Hancock MJ, Kongsted A, Louw Q, Ferreira ML, Genevay $S$, et al. What low back pain is and why we need to pay attention. Lancet. 2018;391(10137):2356-67. DOI

7. St Sauver JL, Warner DO, Yawn BP, Jacobson DJ, McGree ME, Pankratz JJ, et al. Why patients visit their doctors: Assessing the most prevalent conditions in a defined American population. Mayo Clin Proc. 2013;88(1):56-67. DOI

8. Jordan KP, Jöud A, Bergknut C, Croft P, Edwards JJ, Peat G, et al. International comparisons of the consultation prevalence of musculoskeletal conditions using population-based healthcare data from England and Sweden. Ann Rheum Dis. 2014;73(1):212-8. DOI

9. Costa LCM, Maher CG, McAuley JH, Hancock MJ, Herbert $R D$, Refshauge KM, et al. Prognosis for patients with chronic low back pain: Inception cohort study. BMJ. 2009;339:b3829. DOI

10. Verkerk K, Luijsterburg PAJ, Heymans MW, Ronchetti I, PoolGoudzwaard AL, Miedema HS, et al. Prognosis and course of disability in patients with chronic nonspecific low back pain: A 5-and 12-month follow-up cohort study. Phys Ther. 2013;93(12):1603-14. DOI

11. Foster NE, Thomas E, Bishop A, Dunn KM, Main CJ. Distinctiveness of psychological obstacles to recovery in low back pain patients in primary care. Pain. 2010;148(3):398-406. DOI

12. Lee $H$, Hübscher M, Moseley GL, Kamper SJ, Traeger AC, Mansell G, et al. How does pain lead to disability? A systematic review and meta-analysis of mediation studies in people with back and neck pain. Pain. 2015:156(6):988-97. DOI

13. Nusbaum L, Natour J, Ferraz MB, Goldenberg J. Translation, adaptation and validation of the Roland-Morris questionnaire Brazil Roland-Morris. Braz J Med Biol Res. 2001;34(2):203-10. DOI 
14. World Health Organization. Physical status: the use and interpretation of anthropometry. Report of a WHO Expert Committee. Geneva: World Health Organization; 1995. Full text link

15. Wilkens P, Scheel IB, Grundnes O, Hellum C, Storheim K. Prognostic factors of prolonged disability in patients with chronic low back pain and lumbar degeneration in primary care: A cohort study. Spine (Phila Pa 1976). 2013;38(1):65-74. DOI

16. Houde F, Cabana F, Léonard G. Does age affect the relationship between pain and disability? A descriptive study in individuals suffering from chronic low back pain. J Geriatr Phys Ther. 2016;39(3):140-5. DOI

17. Jegan NRA, Brugger M, Viniol A, Strauch K, Barth J, Baum $E$, et al. Psychological risk and protective factors for disability in chronic low back pain - a longitudinal analysis in primary care. BMC Musculoskelet Disord. 2017;18(1):114. DOI

18. Grotle M, Foster NE, Dunn KM, Croft P. Are prognostic indicators for poor outcome different for acute and chronic low back pain consulters in primary care? Pain. 2010;151(3):790-7. DOI

19. Garcia BT, Vieira EBM, Garcia JBS. Relationship between chronic pain and working activities in patients with painful syndromes. Rev Dor. 2013;14(3):204-9. DOI

20. Lin CWC, McAuley JH, Macedo L, Barnett DC, Smeets RJ, Verbunt JA. Relationship between physical activity and disability in low back pain: A systematic review and meta-analysis. Pain. 2011;152(3):607-13. DOI
21. World Health Organization. Global recommendations on physical activity for health. Geneva: World Heal Organization; 2010. Full text link

22. Leeuw M, Goossens MEJB, Linton SJ, Crombez G, Boersma K, Vlaeyen JWS. The fear-avoidance model of musculoskeletal pain: current state of scientific evidence. J Behav Med. 2007;30(1):77-94. DOI

23. Zale EL, Ditre JW. Pain-related fear, disability, and the fear - Avoidance model of chronic pain. Curr Opin Psychol. 2015;5:24-30. DOI

24. Vuori IM, Lavie CJ, Blair SN. Physical activity promotion in the health care system. Mayo Clin Proc. 2013;88(12):1446-61. DOI

25. Brasil. Ministério da Saúde, Secretaria de Vigilância em Saúde, Secretaria de Atenção à Saúde. Política Nacional de Promoção da Saúde. Brasília: Ministério da Saúde; 2010. LFull text link

26. Pinto RZ, Ferreira $\mathrm{PH}$, Kongsted $\mathrm{A}$, Ferreira $\mathrm{ML}$, Maher CG, Kent P. Self-reported moderate-to-vigorous leisure time physical activity predicts less pain and disability over 12 months in chronic and persistent low back pain. Eur J Pain. 2014;18(8): 1190-8. DOI

27. Souza JB. Can exercise induce analgesia in patients with chronic pain? Rev Bras Med Esporte. 2009;15(2):145-50. DOI 